Wissenschaftliche Taschenbücher

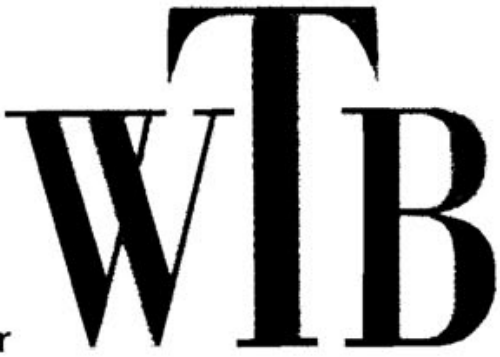

\title{
Biologie
}

\section{Roland Glaser}

Grundriß

der Biomechanik

Akademie-Verlag Berlin 
Eine Auswahl lieferbarer Bände:

Richard Campbell

Mikrobielle Ökologie

\section{Paul Hoffmann}

Photosynthese

\section{Eberhard Hofmann}

Die stofflichen Grundlagen

des Lebens

(Dynamische Biochemie, Teil 1)

\section{Lothar Jäger}

Grundlagen der klinischen

Immunologie
Manfred Knoke/Hannelore Bernhardt Mikroökologie des Menschen

\author{
Wolfgang A. Knorre \\ Pharmakokinetik \\ Theoretische Grundlegen und \\ praktische Anwendungen
}

\author{
Eberhard Teuscher \\ Pharmakognosie \\ Biogene Arzneimittel \\ Teil 1 und 2
}

\author{
Helmut Tschäpe \\ Plasmide \\ Biologische Grundlagen und \\ praktische Bedeutung
}

